\title{
A ESTRUTURA DO VÍNCULO FAMILIAR NA ADOÇÃO TARDIA
}

MARCEL PEREIRA PORDEUS UNIVERSIDADE ESTADUAL DO CEARÁ FORTALEZA, CEARÁ, BRASIL MARCEL.PORDEUS@ALUNO.UECE.BR

ROSEMARY DE ABREU VIANA UNIVERSIDAD SAN CARLOS ASUNCIÓN , PARAGUAI ROSE26360@HOTMAIL.COM 


\section{A ESTRUTURA DO VÍNCULO FAMILIAR NA ADOÇÃO TARDIA}

Resumo: O presente estudo tem por objetivo discutir a construção dos laços afetivos familiares na adoção tardia. Por metodologia, utilizamos a revisão sistemática de literatura em artigos científicos. Como resultado, percebemos que é significante que adotante e adotado queiram construir os vínculos afetivos. A vinculação amorosa entre integrantes de uma mesma família é a chave para respostas e a harmonia familiar.

Palavras-chave: Adoção tardia; Laços afetivos; Vínculo familiar.

\section{LA CONSTRUCCIÓN DE LAZOS FAMILIARES EN ADOPCIÓN TARDÍA}

Resumen: Este estudio tiene como objetivo discutir la construcción de lazos afectivos familiares en la adopción tardía. Por metodología, utilizamos la revisión sistemática de la literatura en artículos científicos. Como resultado, nos damos cuenta de que es significativo que el adoptante y el adoptado adopten lazos afectivos. El vínculo de amor entre los miembros de la misma familia es la clave para las respuestas y la armonía familiar.

Palabras Clave: Adopción tardía; Enlaces afectivos; Vínculo familiar.

\section{THE CONSTRUCTION OF FAMILY BONDS IN LATE ADOPTION}

Abstract: This study aims to discuss the construction of family affective bonds in late adoption. By methodology, we used the systematic literature review in scientific papers. As a result, we realize that it is significant that the adopter and adoptee want to build affective bonds. The loving bond between members of the same family is the key to answers and family harmony. Keywords: Late adoption; Affective bonds; Family bond.

\section{INTRODUÇÃO}

Esta explanação tem por objetivo basilar discorrer a formação do vínculo familiar, os laços afetivos em seu processo de adoção tardia. A origem deste estudo está ligada às implicações do sistema adotivo, bem como as dificuldades já oriundas do processo de adoção tardia e os fatores que influenciam diretamente nesse deficit adotivo. De acordo com Bragança e Júnior (2015), “[...] pode-se entender por adoção, o ato legal ou jurídico, filiação e paternidade entre adotando e adotado".

Esta pesquisa se trata de uma revisão bibliográfica - de cunho qualitativo - realizada por meio de artigos encontrados em base científica de dados. Esta base foi a SciELO (Scientific Eletronic Library). O presente trabalho traz maior ênfase para a problemática principal, podendo assim fazer com que os estudantes se interessem e estudem o assunto, consequentemente cola- 
borando para as pesquisas científicas na área da sociologia e afins. Para realizá-lo, dividimos em três subseções, que se distribuem da seguinte forma: na primeira discutiremos os aspectos teóricos; na segunda a metodologia e; por fim, na terceira, discutiremos os dados apresentados pela bibliografia elencada.

Minayo (2001) acrescenta que a qualitativa responde a questões muito intrínsecas relacionadas às ciências sociais. A autora infere à não quantificação da realidade, que não se enquadra no parâmetro social de estudo. Ou seja, há um emaranhado de interpretações, motivações e valores inerentes a processos e fenômenos que não podem ser minimizados a simples variáveis.

A escolha desse tipo de pesquisa reside na compreensão de que o estado de conhecimento sobre um tema pode servir de suporte na aquisição de uma maior circunscrição sobre o assunto abordado, baseando-se em resultados já obtidos por outros pesquisadores.

Em suma, este trabalho enaltece e analisa o processo adotivo tardio e como ocorre a construção do vínculo familiar após a finalização do processo adotivo. Nesse sentido, sabe-se que a adoção tardia no Brasil é prejudicada por diversos fatores, tais como a falta de interesse dos casais por crianças mais velhas, e as dificuldades impostas pelo próprio sistema para processos adotivos no geral. O processo adotivo é delicado e necessita de atenção em todas as suas etapas, haja vista perpassar questões jurídicas até questões emocionais, que englobam acolhimento, atenção e a afetividade implicada no cotidiano da criança ou adolescente adotado.

Consoante Bragança e Júnior (2015), a atual conjuntura no Brasil quanto a adoção está ligada a inúmeros fatores que são verdadeiros entraves burocráticos, contanto necessários se analisarmos num viés de organização sistemática. Para tanto, os requisitos inerentes a esse processo são, a saber: preferência por adoção única, ou seja, sem irmãos, preferência por sexo, limite de idade, dentre outros. A adoção tardia está ligada a fatores anteriormente citados, que dizem muito acerca do processo, colaborando negativamente para os métodos informativos em relação à adoção no Brasil. A construção de vínculos afetivos e familiares é um procedimento complexo; pois estes surgem de concepções anteriores à adoção, prejudicando a vinculação, fazendo-se necessário extrema aplicação dos adotantes para que os vínculos sejam estabelecidos com sucesso.

De acordo com Sampaio; Magalhães e Feres-Carneiro (2018), por se tra- 
tar de adoção de criança maior, entende-se que essa nova construção se insere em um contexto de mão dupla para adotante e adotado, pois se torna uma adoção mútua capaz de ressignificar o passado, sem precisar apagá-lo, antes disso, construindo a possibilidade de uma nova história integradora. Desta forma, torna-se possível a construção de um futuro capaz de reparar o que possa ter sucedido de ruim e legitimar o que possa ter ficado de bom. Salientamos que a afetividade a ser desenvolvida precisa estar cercada de cuidados e atenção, sendo necessário que o processo de vinculação seja entendido como algo delicado, sendo necessária extrema entrega dos adotantes para que se obtenha sucesso; porém, cabe ressaltar que o acompanhamento individualizado pode ser um grande diferencial nos processos.

\section{O VÍNCULO FAMILIAR E A ADOÇÃO TARDIA}

O vínculo familiar é o principal veículo de fortalecimento das relações. Este precisa ser compreendido como um laço de união imprescindível nas relações afetivas. Em relação aos relacionamentos, estes necessitam da formação destes, que é extremamente fundamental nestes processos emocionais. A primeira etapa para o estabelecimento dos relacionamentos afetivos é a construção do vínculo, que se faz necessário pelo surgimento de fatos e fatores que podem surgir em comum no processo afetivo, seja por meio de um gosto em comum, relações cotidianas e até mesmo de situações desfavoráveis.

Nos casos de construção de vínculo, em adoção tardia, fica explícita a grande necessidade de esforços que precisam vir de todos os envolvidos na construção vincular afetiva. Winnicott (2011) ressalta a importância da experiência vincular nos primeiros anos de vida, relacionando-se à segurança, conforto e atenção, fatores estes que estão ligados à construção saudável de vínculo, isto é, em casos de adoção de crianças maiores o vínculo precisa ser retrabalhado, no intuito de ressignificar os laços perdidos.

Segundo Alvarenga e Bittencourt (2013), o processo adotivo expõe vontades concretas quanto à adoção, revelando concepções psíquicas que podem ligar-se diretamente no processo vincular. Quanto às crianças, expõe-se o desejo de vinculação, ou seja, muitas vezes o processo é idealizado ou pode-se ter associação do passado. Neste caso, ainda pode haver certa rigidez na formação de um novo vínculo, pois o passado vincular da criança pode interferir na formação de um novo vínculo, resultando em transformações de conduta. E, também, as antigas ligações afetivas podem surgir 
para confrontar as novas vinculações afetivas, fazendo com que o adotado mude sua forma de agir para agradar os adotantes, por medo de rejeição.

O vínculo familiar é a base para uma formação saudável de qualquer sujeito, assim como o histórico de construção deste vínculo também, tomando como base a adoção tardia, que se mostra um grande empecilho para o fortalecimento de possíveis vinculações posteriores à adoção tardia. "Os afetos podem ser identificados tanto na necessidade de incorporar o "novo" e superar a ameaça de desintegração, quanto no retorno das representações às práticas diárias" (POMBO-DE-BARROS; ARRUDA, 2010, p. 357).

É importante que entendamos a construção de vínculo como uma necessidade humana, que começa na relação mãe-bebê e se consolida no cotidiano dos integrantes de uma família, não importando suas configurações. O processo de vinculação familiar está presente diante das mais diversas situações, sendo elas negativas ou positivas. Sabendo-se disso, é importante que construamos vínculo com as pessoas a nossa volta, organizando processos psíquicos fundamentais para a formação destas relações.

De acordo com Camargo (2005), a adoção está sendo prejudicada pela falta de conhecimento acerca do processo, sendo assim, necessita ser compreendida para que haja mudanças no cuidado para com as crianças e adolescentes brasileiros. A temática precisa ser discutida para que a socialização sobre a temática aconteça, com o propósito de, a partir desta perspectiva, ocorra a quebra de concepções errôneas. Podemos assim perceber que, com o estudo da temática, a adoção no Brasil é problemática, atuando diretamente para que os casos de adoção tardia sejam significativos. Contudo, observamos outro fator extremamente importante, a falta de informação sobre o assunto se mostrar favorável à problemática.

As dificuldades apresentadas pelas crianças e jovens que passaram por todo o processo institucional e jurídico aparecem como os grandes vilões para o processo vinculativo afetivo. As crianças e adolescentes que estão vivenciando o processo de adoção tardia, oriundas de instituições de acoIhimento, demonstram dificuldades no cotidiano familiar, apresentando resistências e comportamentos procedentes de processos traumáticos, do abandono dos familiares e do abandono social, que se faz presente nos casos de adoção tardia. No Brasil, assim como em grande parte do mundo, muitas crianças são objeto de rejeição e/ou abandono por sua classe parental, e boa parte cresce e se autoeduca no âmbito da instituição do estado, quase sempre mantida e gestada por associações não governamentais e religiosas 
(CAMARGO, 2005).

As instituições de acolhimento não podem fazer o que uma família e o vínculo familiar fariam na vida de uma criança ou adolescente, por isso há uma necessidade de quebrar preconceitos e estabelecer uma consciência acerca deste processo doloroso. É importante que os possíveis candidatos à adoção compreendam quão delicado é o papel a ser desenvolvido pelos mesmos. A construção do vínculo familiar é um grande desafio nos casos de adoção de crianças mais velhas, que muitas vezes foram rejeitadas por motivos incompreensíveis, como a cor da pele, sexo ou até mesmo problemas de saúde; características que não podem ser mudadas, gerando grandes prejuízos emocionais. As inseguranças geradas pelos anos em instituições de acolhimento, gerando barreiras concretas na convivência, nas emoções, na elaboração de sentimentos, torna a vinculação cada vez mais frágil. O processo de vinculação é delicado e afeta diretamente o comportamento do adotado.

A adoção é um dos temas que está encoberto de mitos e, apesar de toda a evolução científica, permanecem pouco estudados. Vargas (1998) relata que a adoção é considerada tardia quando a criança em questão possui 2 anos acima.

Ao discorrermos sobre, falamos de abandono, que pode ser definido como perda do direito da criança de viver no seio de uma família que a ame e a proteja; direito este postulado universalmente. $O$ abandono legal permite respeitar os desejos dos pais de não assumir os filhos, dando a estes novas possibilidades de construir relações vitais que são necessárias e importantes para o seu desenvolvimento. Tem-se o objetivo de assegurar à criança em situação de abandono a integração em um lar e o estabelecimento de laços afetivos entre a mesma e figuras parentais. Deste fato, como assevera a Cartilha de Adoção de crianças e adolescentes da Associação dos Magistrados Brasileiros (AMB), a expressão "adoção tardia" infere ao fato de que “[...] grande parte das crianças em situação de adoção tem mais de 2 anos de idade e que nem todos os pretendentes à adoção desejam bebês como filhos" (AMB, 2007, p. 7).

$A$ adoção tardia fornece às crianças e adolescentes o direito de serem

1 A expressão "adoção tardia", bastante utilizada, refere-se à adoção de crianças maiores ou de adolescentes. Remete à discutível ideia de que a adoção seja uma prerrogativa de recém-nascidos e bebês e de que as crianças maiores seriam adotadas fora de um tempo ideal $[\ldots]$ (AMB, 2007, p. 7). 
adotadas, assim como o direito de terem um lar definitivo, obtendo a partir deste momento todos os direitos elencados a um filho biológico. Proporciona também um papel de grande dimensão social, pois age como meio fundamental para a inserção de crianças e adolescentes em futuras famílias. Vargas (1998, p. 35) esclarece que:

É importante salientar que, toda criança adotada tem um histórico de abandono ou orfandade e tal fato deve ser respeitado e levado em consideração por todos. Quanto maior idade a criança ou o adolescente tiver, mais precisarão da presença constante de uma família, a fim de se sentirem aceitas e amadas, para que assim, possam se adaptar e reescrever uma história totalmente diferente da vida que conheciam, justificando: A adoção tardia, assim como a inter-racial, impossibilitam o "fazer de conta que é biológico", por isso, estas duas modalidades de adoção sumariamente são descartadas.

\section{PROCEDIMENTOS METOdológicos}

Iniciamos a partir dos descritores "adoção tardia" e "vínculo familiar", assim como foi utilizado critérios de inclusão e exclusão, no indexador SciELO. No SCiELO obtivemos em primeira busca 15 (quinze) artigos com o descritor "adoção tardia", dos quais, após refinamento do material, utilizamos os seguintes critérios de exclusão, que foram: artigos não disponíveis na íntegra, artigos que apresentavam repetições; e artigos que fogem do tema proposto, somando um total de sete (7). Quanto ao descritor "vínculo familiar", encontramos duzentos e noventa e cinco 295 artigos, mas nenhum estava inserido no contexto que desejávamos para inclusão na análise. Na junção dos dois descritores supracitados, encontramos dois artigos que refletem na íntegra nosso intento para este ensaio, contudo tais eram repetidos. Sendo assim, selecionamos 8 (oito) artigos por se apresentarem mais adequados aos objetivos da nossa pesquisa, sendo assim distribuídos:

\section{Distribuição dos artigos selecionados na base de dados utilizada na tabela a seguir:}

Quadro 1: Número de artigos selecionados nos portais SciELO - Scientific Eletronic Library Online 


\begin{tabular}{|c|c|c|}
\hline Base & Encontrados & Selecionados \\
\hline SciELO & 15 & 8 \\
\hline
\end{tabular}

Fonte: Elaborado pelo autor.

Existem outros indexadores, porém nos limitamos a este para a construção da nossa pesquisa, devido a explanarem de forma mais perspicaz quais artigos seriam realmente mais adequados. Dos 15 artigos, selecionamos 08 que discorriam sobre o tema adoção e vínculo familiar.

Nas buscas foram utilizados como critérios de inclusão os artigos científicos pertinentes ao tema proposto, publicados em revistas científicas, disponíveis nos idiomas português, inglês e espanhol, publicados no período entre janeiro de 2014 a junho de 2020. Com exceção de alguns artigos, utilizados para agregar ainda mais no desenvolvimento do requerido artigo; tendo em vista a necessidade de complementações necessárias no texto. Como critério de exclusão, optamos por não inserir artigos diferentes dos idiomas citados, e fora do período estipulado. O refinamento do material pesquisado, considerando os critérios de inclusão e exclusão, foi realizado a partir da leitura dos resumos. Concordamos com Ferreira (2002, p. 268) quando declara sobre os resumos que "[...] eles informam ao leitor, de forma rápida, sucinta e objetiva sobre o trabalho do qual se originam”. Acrescenta ainda:

Cada resumo deve ser lido e analisado numa relação de dependência com o trabalho na íntegra, mas também enquanto realidade relativamente independente, produto de uma tensão construída na continuidade e na ruptura com o trabalho que lhe dá origem, numa relação dialética entre os gêneros, entre as condições de sua produção e práticas discursivas (FERREIRA, 2002, p. 270).

$\mathrm{Na}$ etapa seguinte foi feita uma leitura acurada dos artigos, atento ao seu conteúdo e a determinadas características que consideramos relevantes, tais quais: forma que a temática foi desenvolvida e tipo da pesquisa. Após levantamento dos dados, as temáticas foram categorizadas e organizadas para a apresentação dos resultados.

\section{DISCUSSÃO DOS RESULTADOS}

Partindo do recorte metodológico explicitado na sessão anterior, iniciamos a nossa análise de dados a partir do tema adoção. Em nossa análise 
separamos as variáveis, que primeiramente trabalharam os aspectos relacionados à adoção tardia, para posteriormente trabalharmos com vínculo e depois construirmos a relação entre esses dois elementos.

De acordo com o Estatuto da Criança e do Adolescente, os filhos havidos ou não da relação do casamento, ou por adoção, terão os mesmos direitos e qualificações, proibidas quaisquer designações discriminatórias relativas à filiação, conforme o Art. $20^{\circ}$ do ECA (BRASIL, 1990).

Santos (2015, p. 5) afirma que "[...] a adoção é uma das formas de garantir à criança e ao adolescente, que se encontrão em instituições de acolhimento, o direito à convivência familiar e comunitária”. A Constituição, em seu Art. $227^{\circ}$, trata da proteção da criança e do adolescente e estabelece que a adoção será assistida pelo Poder Público:

É dever da família, da sociedade e do Estado assegurar à criança, ao adolescente e ao jovem, com absoluta prioridade, o direito à vida, à saúde, à alimentação, à educação, ao lazer, à profissionalização, à cultura, à dignidade, ao respeito, à liberdade e à convivência familiar e comunitária, além de colocá-los a salvo de toda forma de negligência, discriminação, exploração, violência, crueldade e opressão (BRASIL, 1988, online²).

Segundo dados do Cadastro Nacional de Adoção - CNA, em todo o Brasil há 8.602 crianças e adolescentes aptos à adoção, e 43.638 pretendentes à adoção (CNJ, 2019). Percebe-se que a razão desse descompasso se deve ao fato de que o perfil de crianças e adolescentes desejado pelos adotantes não é o mesmo existente nas instituições de acolhimento das mesmas. Ainda acompanhando os dados do cadastro de adoção, percebemos que os perfis que se sobressaem hoje são os de crianças brancas, recém-nascidas, saudáveis e sem irmãos.

Bragança e Junior (2015) compreendem que no contexto das políticas públicas de adoção, faz-se necessário compreendermos o que vem a ser adoção. Algumas definições trazem a compreensão do que é adotar. "Ato ou efeito de alguém aceitar, legalmente, como filho, um filho de outrem”. "O ato solene pelo qual se cria entre o adotante e o adotado, relação de paternidade e filiação". "A adoção é o ato civil pelo qual alguém aceita um estranho na qualidade de filho". "Ato jurídico que estabelece entre duas

2 Disponível em: http://www.planalto.gov.br/ccivil_03/Constituicao/Constituiçao. htm. Acesso em: 16 jan. 2021. 
pessoas, relações civis de paternidade e de filiação". Dessa forma, pode-se entender por adoção, o ato legal ou jurídico, filiação e paternidade entre adotando e adotado.

Além do ato legal, adotar é um ato nobre de amor e responsabilidade, mas que poderá ser desfeito se houver maus tratos ao adotado, da mesma forma que na família biológica. De tal modo a adoção possibilita filhos a quem não pode tê-los biologicamente e pais às crianças e adolescentes desamparados, proporcionando a estes uma vida digna, por meio da educação, proteção, afeto, saúde, criando no decorrer do tempo um vínculo familiar.

Mello et al. (2016) salientam que ao abordarmos o tema da adoção, automaticamente pensamos no abandono. Atualmente, nos referimos às casas de abrigo como um lugar em que as crianças são acolhidas, devido ao abandono pela família. Poucos casos acontecem de pais que deixam espontaneamente os filhos nesses abrigos. A criança que anseia por uma família sofre negligências, não só por questões sociais, mas principalmente de afeto.

Couto et al. (2014) afirmam que o ato de adoção de uma criança envolve não só um longo e difícil processo judicial, mas principalmente complexas questões subjetivas relativas ao casal adotante e à criança. Do lado do casal, há o anseio e a espera, sabendo-se que muitas vezes, nas adoções, tem-se um trabalho árduo de elaboração psíquica. Em outros casos, alguns casais vão atrás de adotar pela impossibilidade de ter um filho biológico. É preciso trabalhar a mudança do desejo de ter um filho por ter um filho adotivo, mesmo esta com todas as dificuldades que podem apresentar; um filho adotivo não poderá nunca corresponder ao filho imaginado pelos pais.

A criança com história de abandono precoce precisará fazer um trabalho de luto para que possa, de alguma forma, elaborar sua história. Poder voltar a confiar em um adulto é um grande desafio que a criança enfrentará, por isso se faz necessário que a família adotante elabore suas próprias dificuldades e, que esta não dê um passo atrás diante das marcas sofridas da história do filho tardio que está acolhendo, sempre dando atenção a verdade da criança e apostando na sua capacidade de criar novos laços. Freitas (2017) destaca que a institucionalização, muitas vezes, é a melhor opção para a criança ou adolescente que vem de uma história difícil e complicada no seu âmbito familiar.

Geralmente, o sonho de uma criança institucionalizada é ter uma família, isso pode ser manifestado por meio dos discursos, brincadeiras e desenhos, 
porém, quando estão diante da possibilidade de realização desse sonho, vivem uma ambivalência entre a aceitação e a rejeição dos adotantes. Reações de desconforto por parte da criança não devem ser interpretadas necessariamente, como inadaptação ou rejeição, pois muitas vezes refletem a busca de acolhimento para a construção desses novos vínculos. A construção de um vínculo de filiação exige esforço, dedicação, trabalho e, sobretudo, tempo. Nos casos de adoção tardia, aceitar o outro em sua integralidade e originalidade se dá de forma bem desafiadora, visto que se aprenderá a lidar com as dificuldades e limitações da criança em questão. Nesse viés, existem muitos grupos de apoio que agem no intuito de fomentar a adoção tardia no Brasil, a exemplo disso podemos citar o projeto Adoção Tardia ${ }^{3}$, que surgiu em um canal no Youtube ao contar histórias instigantes de famílias constituídas por adoção. Esse trabalho é resultado de uma monografia de graduação em Design Visual, da Universidade Federal do Rio Grande do Sul, da discente chamada Simone Uriartt, filha por adoção, que teve por inspiração discorrer sua própria história familiar, no intento de dirimir os entraves existentes entre o número de pretendentes e de crianças aptas a serem adotadas (ADOÇÃO TARDIA, 2021).

Para o sucesso dessa forma de adoção é necessária uma política transparente e aberta entre os membros familiares, para que dessa forma os vínculos emocionais e sociais sejam constituídos e mantidos, e não gerando mais conflitos e desconfortos. Esse processo exige paciência, perseverança e sensibilidade por parte dos adotantes para responder as necessidades pouco conhecidas da criança. Adotar uma criança não deve ser por reparação de um problema ou dificuldade, mas sim que essa criança ou adolescente mereça um novo recomeço, uma nova vida. Sendo necessário ter em mente que a prioridade são os interesses das crianças, e estas devem vir em primeiro lugar, procurando não focar, primeiramente, nos anseios do adotante. Porém, não é o que ocorre na prática, pois na maioria dos casos as famílias vão aos abrigos em busca de recém-nascidos com cor de pele clara, criando assim um estereótipo para a criança desejada. Chegando lá, se deparam com várias crianças maiores e adolescentes, quase sempre de pele escura.

Morelli et al. (2015) compreendem que um dos motivos que explica a procura por bebês é o fato de os adotantes acreditarem que, por se tratar de

3 Disponível em: https://observatoriozsetor.org.br/carrossel/adocao-tardia-quando-nao-se-define-idade-para-amar/. Acesso em: 18 jan. 2021. 
recém-nascidos, estes serão mais fáceis de educar. Quando se discorre sobre a adoção tardia ou adoção da criança em idade maior, é comum a crença de que crianças maiores trazem maus hábitos, apresentam problemas na adaptação da nova família, trazem o conhecimento sobre sua adoção e fortes lembranças do passado que ainda são muito presentes em sua vida, o que Ihes traria futuros problemas. Os adotantes temem que crianças maiores não sejam passíveis de serem educadas. Forma-se uma expectativa toda negativa neste sentido.

As crianças negras, com mais de dois anos de idade, portadoras de alguma deficiência ou que possuem algum histórico com problemas de ordem biológica, estão destinadas a passar um período muito extenso nas casas de abrigo; estas ainda são vitimadas por múltiplos abandonos: o abandono da família biológica que, por motivos diversos, são impedidas de manter os seus filhos; o abandono do estado que, por meio das limitadas legislações e deficitárias políticas públicas, tem os "braços engessados" para o acolhimento das crianças e adolescentes e; por fim, o abandono da sociedade, que ainda não entendeu o sentido pleno do termo inclusão. Acerca da construção do vínculo familiar, discutiremos possíveis alternativas para a construção dos vínculos, o processo de adaptação e as repercussões, os sentimentos oriundos do processo e a terapia familiar, como opções para a construção e fortalecimento dos vínculos. Segundo os autores Sampaio; Magalhães e Feres-Carneiro (2018), as dificuldades mais pertinentes durante o processo de adaptação, são: imposição de regras; comportamento agressivo; falta de segurança jurídica; atraso escolar; regressão infantil; e adaptação à rotina familiar.

Observa-se que o processo de vinculação é carente e frágil por si só, isto é, além de dificuldades já tão enraizadas sobre a vinculação familiar entre adotado e adotantes, ainda persiste questões que vão além das mais visíveis, como é o caso do emocional destes indivíduos. A vinculação emocional é extremamente sensível, logo, para a obtenção de êxito nesse processo, faz-se necessária e indispensável a colaboração de profissionais com experiência em tais processos. Ainda se faz necessária a total atenção dos adultos envolvidos, do grupo familiar e dos demais vinculados, para que a confiança seja estabelecida diante de aspectos que são extremamente negativos, que podem acabar por tomar a frente nas questões emocionais do adotado.

A convivência precisa acontecer de forma delicada, mas ao mesmo tempo precisa acontecer naturalmente, ou seja, é necessário ter-se doses de cuida- 
do, com boa pitada de espontaneidade. A criança precisa sentir-se querida e cuidada, entretanto, o espaço para que se sinta simplesmente criança é fundamental. Esta vinculação precisa ocorrer sem grandes dificuldades, apesar das questões de adaptação e das demais dificuldades provenientes do passado de abandono da criança. As atenções precisam ter enfoque absoluto no processo de formação de vínculo, e o adotante tem um papel de absoluta importância para o desenvolvimento sadio da criança, como um todo. Além disso, a família desempenha papel único e fundamental na constituição do sujeito, seja ele um adolescente, criança ou bebê. O desenvolvimento e a estruturação sadia do sujeito são oriundos do contato com o meio e com o outro, que necessariamente precisa ser sadio, independente das estruturações em que se desenvolvem (MACHADO; FERREIRA; SERON, 2015).

As ligações que constituímos na infância e na juventude são a chave para o desenvolvimento do emocional no processo de vinculação. $O$ respeito que se é adquirido, a admiração, cria laços que ficam para sempre. As emoções provenientes dessas relações nos dirão como vamos responder a estímulos, que poderão variar de acordo com os acontecimentos, que independem de nossas vontades e quereres, só então percebemos o quanto as vinculações afetivas constituídas são expressivas na vida adulta. "Evidenciou-se a função ativa da criança adotada em sua introdução na genealogia da família, tendo ela uma significativa participação na validação do parentesco adotivo, a partir da viabilização de um laço amoroso com os demais membros da família" (MACHADO; FERES-CARNEIRO; MAGALHÃES, 2015, p. 450).

É necessário que a ligação se dê entre ambas as partes e, para se formar vínculo, é importante que adotante e adotado queiram construir esses vínculos. A vinculação amorosa entre integrantes de uma mesma família é a chave para perguntas e respostas. Raínho (2015, p. 25) assevera que “[...] a demonstração de afeto é fundamental para o vínculo afetivo; mostrar-se interessado no que o sujeito faz e diz é extremamente importante para que essa construção tão delicada aconteça de forma concreta". Contudo, ainda é necessário explicitar o afeto, mostrar que o carinho recebido por parte do sujeito adotado é importante na relação que está se desenvolvendo.

Conclui-se que, apesar de ser de grande importância as relações iniciais na vida de um bebê, uma criança que sofreu privações ou de privações e que foi retirada ou abandonada por sua família consanguínea pode encontrar na família por adoção um ambiente suficientemente bom e seguro - com pais que entendam e respei- 
tem suas necessidades, e ofereçam um ambiente acolhedor - que propicie um desenvolvimento emocional saudável (ALVES; HUEB; SCORSOLINI-COMIN, 2017, p. 281).

Parte do processo de vinculação é a segurança que precisa ser passada de adotante para adotado. Essa segurança diz respeito à afeto, moradia, atenção, que quer dizer envolvimento direto com as necessidades citadas anteriormente, imprescindíveis para o desenvolvimento do vínculo familiar. Segundo Bicca e Grzybowski (2014), o fato de o sujeito ter idade mais avançada seria um fator positivo na construção de vínculo. O sujeito seria mais consciente, sendo assim, o processo se dá de maneira mais tranquila, contribuindo para que a construção da rotina familiar também aconteça mais facilmente. A terapia familiar atua como opção sólida no fortalecimento dos vínculos, atuando como um importante instrumento de consolidação dos vínculos, respeito às singularidades e incertezas provenientes do processo. "Atua fortemente nas certezas do processo, dando contribuições importantes no crescimento e funcionamento da nova dinâmica familiar, levando em conta as subjetividades de cada um" (MAESTRI et al., 2017, p. 393).

$\mathrm{Na}$ análise desses artigos discute-se que a criança que anseia por uma família sofre negligências, não só por questões sociais, mas principalmente de afeto. Desse modo, neste modelo, onde a adoção é pautada no desejo do adotante, deve-se então ser mudado, a fim de possibilitar um maior acoIhimento dessas crianças. Neste ensaio, foi discutido possíveis alternativas para a construção dos vínculos, o processo de adaptação e as repercussões, os sentimentos oriundos do processo e a terapia familiar como opções para a construção e fortalecimento dos vínculos.

\section{CONCLUSÕES}

A referida pesquisa nos aponta a necessidade de mudanças de paradigmas, que são muitas vezes distorcidas, como a preferência dos casais por determinada idade, sexo, raça; deixando claro que a deficiência do sistema adotivo muitas vezes parte da discriminação dos pretendentes à adoção, gerando e disseminando mitos e estigmas. Os preconceitos presentes na sociedade atual implicam diretamente no processo de adoção. Considerando a pesquisa realizada, nota-se que os fatores acima, juntamente a outros, como a preferência por crianças sem irmãos, sem deficiências ou problemas crônicos de saúde, contribuem de forma constante e negativa na demora do 
processo de adoção.

Percebemos ainda que a institucionalização tem forte impacto nestas crianças que estão em busca de uma nova família, seja por motivo de abandono ou por passar longos períodos no abrigo sendo rejeitadas. Geralmente apenas crianças de até três anos conseguem uma família no Brasil, fazendo com que as crianças mais velhas cresçam institucionalizadas ou adotadas por estrangeiros. É nesse contexto de pobreza no Brasil que encontramos a maioria dos casos de abandono de crianças: o abandono pela negligência ou o abandono nas ruas, nos lixos, nas maternidades e em instituições. É imprescindível um estudo que busque investigar como é a percepção de crianças que vivem em instituições em relação ao tema da adoção, assim como saber como estas se sentem, visando dar voz a elas, pois se encontram na fila de espera por uma nova família. Analisa-se assim quais as perspectivas das mesmas para lidar com todo esse processo de espera e anseio.

É importante mais pesquisas que favoreçam uma maior reflexão em relação a adoção tardia, a fim de possibilitar maior entendimento sobre a forma que se dá esse processo de tornar-se pai e mãe, assim como pesquisas relacionadas a motivação dos pais adotantes no Brasil, e mais materiais sobre o processo de adoção e a forma como se desenvolve essa parentalidade entre adotante e adotado.

Faz-se necessário que o pesquisador esteja imerso no campo de estudo, referente à temática que deseja estudar, no intento de buscar subsídios para o melhor aproveitamento desse material de pesquisa, contribuindo dessa forma para um melhor entendimento deste tema tão significativo para a sociedade. É importante a criança querer fazer parte desta nova família, participar ativamente deste processo de acolhimento. Por outro lado, o adotante fica numa posição em que ele possa, num processo em questão, ocupar o lugar de passividade, ou seja, dele se deixar ser escolhido pela criança. A criança tem que se sentir livre para fazer essa escolha, determinando o seu futuro. Deste fato, problemas de convivência e adaptação são passíveis de ocorrer nos primeiros meses, assim como barreiras e bloqueios da criança, no qual podem se tornar um grande desafio para os adotantes. Portanto, a criança também precisa aceitar os novos pais; retirar de sua mente a imagem idealizada e construída muitas vezes nos abrigos em que passou.

\section{REFERÊNCIAS}

ADOÇÃO TARDIA. Nossa origem. Disponível em: https://www.adocaotardia.com/sobre- 
CADERNOS DE COMUNICAÇÃO

UNIVERSIDADE FEDERAL DE SANTA MARIA

-nos. Acesso em: 18 jan. 2021.

ALVES, Jéssika Rodrigues; HUEB, Martha Franco Diniz; SCORSOLINI-COMIN, Fabio. Desenvolvimento emocional de crianças que vivenciaram o processo adotivo: revisão integrativa da literatura. Contextos Clínicos, v. 10, n. 2, Jul./Dez. 2017. Disponível em: <encurtador. com.br/eowA3>. Acesso em: 30 abr. 2020.

ALVARENGA, Lidia Levy de; BITTENCOURT, Maria Inês Garcia de Freitas. A delicada construção de um vínculo de filiação: o papel do psicólogo em processos de adoção. Pensando fam., Porto Alegre, v. 17, n. 1, p. 41-53, jul. 2013. Disponível em: <encurtador.com.br/wFPVX>. Acesso em: 05 abr. 2020.

ASSOCIAÇÃO DOS MAGISTRADOS BRASILEIROS. Cartilha da adoção de crianças e adolescentes no Brasil. Disponível em: <encurtador.com.br/uAJPX>. Acesso em: 05 abr. 2020.

BICCA, Amanda; GRZYBOWSKI, Luciana Suárez. Adoção tardia: percepções dos adotantes em relação aos períodos iniciais de adaptação. Contextos Clínic., São Leopoldo, v. 7, n. 2, p. 155-167, dez. 2014. Disponível em: <encurtador.com.br/eAGO8>. Acesso em: 20 mar. 2020.

BRASIL. [Constituição (1988)]. Constituição da República Federativa do Brasil de 1988. Brasília, DF: Presidência da República, [2016]. Disponível em: http://www.planalto.gov.br/ ccivil_03/Constituicao/Constituiçao.htm. Acesso em: 16 jan. 2021.

BRASIL. Lei Federal n. 8069, de 13 de julho de 1990. ECA _ Estatuto da Criança e do Adolescente.

BRAGANÇA, Renata Resende; JUNIOR, Antônio Alexandre Pereira. Crianças institucionalizadas, a demora na adoção. v. 23, n. 3, p. 89-97, Jul./Set. 2015. Disponível em: <encurtador.com.br/wzGS9>. Acesso em: 25 maio 2020.

CADASTRO NACIONAL DE ADOÇÃO (CNA). Disponível em: <http://www.cnj.jus.br/cnanovo/pages/publico/index.jsf>. Acesso em: 30 maio 2020.

CAMARGO, Mário Lázaro. A adoção tardia no Brasil: desafios e perspectivas para o cuidado com crianças e adolescentes. In: SIMPOSIO INTERNACIONAL DO ADOLESCENTE, 2., 2005, São Paulo. Proceedings online... Disponível em: <encurtador.com.br/clL58>. Acesso em: 01 jun. 2020.

COUTO, Olímpia Helena Costa. Os caminhos cruzados da adoção: do abandono precoce à última esperança. Reverso, Belo Horizonte, v. 36, n. 68, p. 63-69, dez. 2014. Disponível em: <encurtador.com.br/juVZo>. Acesso em: 24 maio 2020.

FERREIRA, Norma Sandra de Almeida. As pesquisas denominadas "estado da arte". Educação \& Sociedade, v. 23, n. 79, Ago./2002. Disponível em: <http://www.scielo.br/pdf/es/ v23n79/10857.pdf>. Acesso em: 02 jun. 2020.

FREITAS, Caroline. Criança institucionalizada: a importância da preparação na vivência do processo de adoção. Abril, 2017. Disponível em: <http://www.psicologia.pt/artigos/textos/ TL0406.pdf>. Acesso em: 25 abr. 2018.

MACHADO, Rebeca Nonato; FERES-CARNEIRO, Terezinha; MAGALHAES, Andrea Seixas. Parentalidade adotiva: contextualizando a escolha. Psico (Porto Alegre), Porto Alegre, v. 46, n. 4, p. 442-451, dez. 2015. Disponível em: <encurtador.com.br/atDMN>. Acesso em: 
22 jun. 2020.

MACHADO, Letícia Víer; FERREIRA, Rodrigo Ramires; SERON, Paulo César. Adoção de crianças maiores: sobre aspectos legais e construção do vínculo afetivo. Estudos interdisciplinares em Psicologia, Londrina, v. 6, n. 1, p. 65-81, jun. 2015. Disponível em: <encurtador.com.br/KU045>. Acesso em: 22 maio 2020.

MAESTRI, Caroline Fátima Rodrigues; RAMOS, Jéssica; CAMASSOLA, Ketllyn; SILVA, Luanda Pessoa da; SILVESTRE, Raquel Brizola de Oliveira; MAZZOTTI, Silvia Maria Pedrotti. Os desafios da família contemporânea na adoção tardia de crianças e adolescentes. Caxias do Sul - RS, de 02 a 04 de outubro de 2017. Disponível em: <encurtador.com.br/qxzKM>. Acesso em: 22 jul. 2020.

MELLO, Magda Medianeira de; LUZ, Kelvin Giehl da; ESTEVES, Cristiane da Silva. Adoção Tardia: Contribuições do Projeto DNA da Alma de Farroupilha/RS. Canoas, v. 4, n. 1, 2016. Abril, 2016. Disponível em: <encurtador.com.br/DLN59>. Acesso em: 24 maio 2020.

MINAYO, Maria Cecília de Souza (org.). Pesquisa Social. Teoria, método e criatividade. 18. ed. Petrópolis: Vozes, 2001. Disponível em: <encurtador.com.br/InuCV>. Acesso em: 28 jun. 2020.

MORELLI, Ana Bárbara; SCORSOLINI-COMIN, Fabio; SANTEIRO, Tales Vilela. 0 "lugar" do filho adotivo na dinâmica parental: revisão integrativa de literatura. Psicol. clin., Rio de Janeiro , v. 27, n. 1, p. 175-194, 2015. Disponível em: <encurtador.com.br/fnGSU>. Acesso em: 15 abr. 2020.

POMBO-DE-BARROS, Carolina Fernandes; ARRUDA, Angela Maria Silva. Afetos e Representações Sociais: Contribuições de um Diálogo Transdisciplinar. Psicologia: Teoria e Pesquisa. Abr./Jun., 2010, v. 26 n. 2, p. 351-360. Rio de Janeiro. Disponível em: <http://www. scielo.br/pdf/ptp/v26n2/a17v26n2>. Acesso em: 12 dez. 2020.

RAINHO, Rita Angélica Da Cruz. Começou há dois anos... A primeira etapa do ciclo vital na família por adoção. Universidade do Porto, jun. 2015. Disponível em: <encurtador.com.br/ ghwl7>. Acesso em: 22 jun. 2020.

SANTOS, Aline da Silva Oliveira. Desafios a adoção de crianças e adolescentes no Brasil. Universidade católica de Brasília, dez. 2015. Disponível em: <encurtador.com.br/rwHQ5>. Acesso em: 11 jun. 2020.

SAMPAIO, Débora da Silva; MAGALHAES, Andrea Seixas; FERES-CARNEIRO, Terezinha. Pedras no caminho da adoção tardia: desafios para o vínculo parento-filial na percepção dos pais. Temas psicol., Ribeirão Preto, v. 26, n. 1, p. 311-324, mar. 2018. Disponível em: <encurtador.com.br/glpK8>. Acesso em: 02 mar. 2020.

VARGAS, Marlizete Maldonado. Adoção Tardia: da família sonhada à família possível. São Paulo: Casa do Psicólogo, 1998.

WINNICOTT, D.W. A família e o desenvolvimento individual. Trad. I. C.S. Ortiz. São Paulo: Martins Fontes, 2011. 


\section{Marcel Pereira Pordeus}

Mestrando em Planejamento e Políticas Públicas pela Universidade Estadual do Ceará (UECE) - Conceito 4 (CAPES). Graduado em Letras: Português / Literaturas pela Universidade Federal do Ceará. Fui bolsista do Conselho Nacional de Desenvolvimento Científico e Tecnológico (CNPq) e membro do GETEME - UFC.

E-mail: marcel.pordeus@aluno.uece.br

\section{Rosemary de Abreu Viana}

Doutora em Ciências da Educação pela Universidade San Carlos em Asunción - PY, em 2015. Com diploma reconhecido no Brasil pela Universidade Federal de Alagoas - UFAL. Graduada em Letras Português pela UFC desde 1997. Especialista em Língua Portuguesa e Professora desde março de 1998. E-mail: rose26360@hotmail.com 